\title{
EŞ KANALLI AÇISAL PRESLEME (EKAP) UYGULANAN GEMİ İNŞA ÇELİĞİNİN İÇYAPI VE MEKANIKK ÖZELLİKLERINNIN İNCELENMESİ
}

\author{
Dursun Murat SEKBAN* \\ Karadeniz Teknik Üniversitesi, Sürmene Deniz Bilimleri Fakültesi, Gemi Makineleri İşletme Mühendisliği, \\ Trabzon, Türkiye
}

\begin{tabular}{l}
\hline Anahtar Kelimeler \\
\hline Eş Kanallı Açısal Presleme, \\
Gemi İnşaatı, \\
Düşük Karbonlu Çelik, \\
İçapı, \\
Mekanik Özellik.
\end{tabular}

Öz

Yüksek mukavemetli çeliklerin düşük kaynak edilebilirlik ve şekillendirilebilmeleri nedeniyle, gemilerde yüksek dayanım istenen kısımlarda düşük-orta mukavemetli çelikler kalınlıkları arttırılarak kullanılmaktadır. Daha kalın sacların kullanılması beraberinde ağırlığın ve yakıt tüketiminin önemli ölçüde artmasını getirmektedir. $\mathrm{Bu}$ bağlamda düşük-orta mukavemetli gemi imalat çeliklerinin aşırı plastik deformasyon yöntemleri veya ısıl işlemler uygulanarak dayanımlarının geliştirilmesi oldukça önemlidir. Așırı plastik deformasyon (APD) yöntemleri ile malzemenin kimyasal bileşiminde herhangi bir değişiklik yapmadan tane boyutunu küçülterek malzemenin mukavemetini arttırmak son dönemlerde sıklıkla kullanılmaktadır. APD yöntemleri arasında eş kanallı açısal presleme (EKAP) yöntemi yüksek oranda tane inceltme ve mukavemet arttırma özelliği bakımından öne çıkmaktadır. Literatür incelendiğinde EKAP yönteminin herhangi bir gemi inşa çeliğine uygulamasının olmadığı açıkca görülmektedir. Bu yüzden yapılan çalışmada gemi inşaatından yoğun bir kullanıma sahip düşük-orta mukavemetli Grade A gemi inşa çeliğine $300{ }^{\circ} \mathrm{C}^{\prime}$ de tek paso EKAP uygulanmış ve EKAP sonrası çelikteki içyapısal ve mekanik özelliklerinin değişimleri incelenmiştir. İncelemeler sonucunda EKAP sonrası ortalama tane boyutunun $25 \mu \mathrm{m}$ seviyesinden $7 \mu \mathrm{m}$ seviyesine indiği ve tane boyutunda meydana gelen bu azalmanın sonucu olarak sertlik ve mukavemet değerlerinin ana yapıya göre önemli oranda arttığı belirlenmiştir. Öte yandan EKAP sonrası numunelere aşınma ve şekil verilebilirlik deneyleri de uygulanmıș ve aşınma davranışının bir miktar iyileștiği şekil verilebilirliğin ise EKAP sonrası kötüleștiği belirlenmiștir.

\section{INVESTIGATION OF THE MICROSTRUCTURAL AND MECHANICAL PROPERTIES OF EQUAL CHANNEL ANGULAR PRESSED (ECAPED) SHIP BUILDING STEEL}

\begin{tabular}{ll}
\hline Keywords & Abstract \\
\hline $\begin{array}{l}\text { Equal Channel Angular, } \\
\text { Pressing, }\end{array}$ & $\begin{array}{l}\text { Low-medium strength steels are used by increasing their thickness in parts where } \\
\text { high strength is required on ships due to the low weldability and formability of high- } \\
\text { Low Carbon Steel, }\end{array}$ \\
Microstructure, & strength steels. The use of thicker plates brings about a significant increase in the \\
Mechanical Properties. & improve the strength of low-medium strength shipbuilding steels by applying \\
& severe plastic deformation methods or heat treatments. Grain refinement via severe \\
plastic deformation (SPD) seems to be an essential strengthening mechanism \\
without changing the chemical composition of metallic materials. Among SPD \\
methods, equal channel angular pressing (ECAP) is one of the most commonly used \\
one due to its high grain refinement capacity. When the literature is examined, it is \\
clearly seen that ECAP is not applied to any shipbuilding steel before. Therefore, in \\
this study, one pass ECAP at 300 0C to low-medium strength shipbuilding steel \\
(Grade A) which has intensively used in the shipbuilding industry and the changes \\
in the microstructural and mechanical properties of steel after ECAP were \\
investigated. After investigations, it was determined that the average grain size after
\end{tabular}

\footnotetext{
* ilgili yazar / Corresponding author: msekban@ktu.edu.tr, +90-462-377-8077
} 
ECAP decreased from $25 \mu \mathrm{m}$ (base material) to $7 \mu \mathrm{m}$ and as a result of this, hardness and strength values increased significantly compared to the base material. On the other hand, wear and formability tests were applied after and before ECAP and it was determined that while a slight improvement was obtained in wear behavior, formability behavior deteriorated after ECAP.

\section{Alıntı / Cite}

Sekban, D.M., (2020). Eş Kanallı Açısal Presleme (EKAP) uygulanan Gemi İnșa Çeliğinin İçyapı ve Mekanik Özelliklerinin İncelenmesi, Mühendislik Bilimleri ve Tasarım Dergisi, 8(1), 240-251.

\begin{tabular}{l|l|l}
\hline Yazar Kimliği / Author ID (ORCID Number) & Makale Süreci / Article Process \\
\hline D.M. Sekban, 0000-0002-7493-1081 & Başvuru Tarihi / Submission Date & 27.05 .2019 \\
& Revizyon Tarihi / Revision Date & 17.08 .2019 \\
& Kabul Tarihi / Accepted Date & 25.10 .2019 \\
& Yayım Tarihi / Published Date & 20.03 .2020 \\
\hline
\end{tabular}

\section{Giriş (Introduction)}

Gemilerde ahşap, kompozit malzemeler ve aluminyum alaşımları kullanılsa da bu malzemelerle üretilen gemilerde özellikle dayanım anlamında yaşanan sıkıntılardan ötürü gemi inşaatında çelik malzemelerin kullanımı ön plana çıkmaktadır (Eyres, 2001). Çelikler ayrıca şekil verilebilirlik, kaynak edilebilirlik ve maliyetleri göz önüne alındığında da kullanılan diğer malzemelere büyük üstünlükler sağlamaktadır. Gemilerde kullanılan çelikler en genel anlamda düșük-orta mukavemetli çelikler ve yüksek mukavemetli çelikler olarak ikiye ayrılabilir. Düşükorta mukavemetli gemi inşa çeliklerinde karbon oranı yaklaşık \%0,2 seviyelerindedir. Bu tip çeliklerde dayanımı arttırması nedeniyle Mn ve Si elementleri de bulunmaktadır (Bhadeshia ve Honeycombe 2011; Klepaczko vd., 2009). Yüksek mukavemetli gemi inşa çelikleri ise düşük-orta mukavemetli gemi imalat çeliklerine göre daha yüksek oranda $\mathrm{Mn}$ ve $\mathrm{Cu}$ elementleri içerdiğinden; daha yüksek mukavemet, sertlik ve korozyon direnci gösterirler. Ayrıca bu tür çelikler düşük-orta mukavemetli gemi imalat çeliklerinde bulunmayan ve yapıya yüksek mukavemet, yüksek sertlik, iyi korozyon dayanımı veren ve tane irileşmesini engelleyici $\mathrm{Nb}, \mathrm{V}, \mathrm{Ti}$ ve $\mathrm{N}$ gibi elementleri de ihtiva ederler (Klepaczko vd., 2001). Yüksek mukavemetin istendiği gemi kısımlarında yüksek mukavemetli çelikler kullanılsa da bu tür çeliklerin kullanılmasını zayıf kaynak edilebilirlik ve düşük şekil verilebilirlik gibi kısıtlayan bazı faktörler vardır. Bu faktörler göz önüne alındığında gemilerde yüksek dayanımın istenildiği yerlerde genellikle daha kalın saclar kullanılarak yüksek mukavemet gereksinimi karşılanmaktadır. Yüksek mukavemet elde etmek adına daha kalın sacların kullanılması gemilerde ağırlığın dolayısıyla da yakıt tüketiminin önemli ölçüde artışına neden olmaktadır. Bu nedenle düşük-orta mukavemetli gemi imalat çeliklerinin uygulanacak çeşitli yöntemlerle mukavemetlerinin geliştirilmesi gemi imalat sektörüne önemli bir katkı olacaktır.

Çeşitli aşırı plastik deformasyon (APD) yöntemleri ile malzemenin kimyasal bileşiminde herhangi bir değişiklik yapmadan tane boyutunu küçülterek malzemenin mukavemetini arttırmak son dönemlerde sıklıkla kullanılmaktadır. Bu APD yöntemleri arasında eş kanallı açısal presleme (EKAP) yöntemi yüksek oranda tane inceltme ve mukavemet arttırma özelliği açısından diğer yöntemler arasında ön plana çıkmaktadır. EKAP yöntemi eş kesit alanına sahip iki kanaldan düşey kanala yerleştirilen numunenin hidrolik bir pres yardımıyla itilerek yatay kanaldan çıkarılması prensibine dayanmaktadır (Demirtaş, 2017). Bu işlem sırasında numunede yatay kanaldan düşey kanala geçiş sırasında kayma düzleminde gerçekleşen basit kayma ile yoğun bir plastik deformasyon gerçekleşmektedir. EKAP yöntemi ile ilgili daha detaylı bilgiye literatürdeki çalışmalardan ulaşılabilinmektedir (Valiev vd., 2000; Furukawa vd., 2001; Valiev ve Langdon 2006; Langdon, 2007). EKAP yöntemi kullanılarak malzemelerin mekanik özelliklerinin geliştirilmesi üzerine yapılan çalışmalar incelendiğinde çalışmaların yoğunlukla çinko, aluminyum ve bakır gibi hafif alaşımlar üzerine yoğunlaştığı görülmektedir. Demirtaş ve arkadaşları yaptıkları farklı çalışmalarda değișen oranlardaki Zn-Al alaşımlarına EKAP uygulamış ve EKAP sonrasında tane boyutunun oldukça inceldiğini ve malzemenin süperplastik özellik göstermeye başladığını belirlemişlerdir (Demirtas vd., 2015; Demirtas vd., 2018). Ebrahimi ve arkadaşları yaptıkları çalışmada Cu-Sn alaşımının EKAP sonrasında tane boyutunun mikron altı seviyelere düștüğünü, bununla birlikte korozyon dayanımının da arttığını belirlemişlerdir (Ebrahimi vd., 2019). Smirnov ve Konstantinov saf bakıra EKAP uygulamış ve EKAP sonrasında malzemenin ultra ince taneli bir içyapı sergilediğini, mukavemet ve darbe dayanımı değerlerinin de yükseldiğini rapor etmișlerdir (Smirnov ve Konstantinov 2018). Horikiri ve arkadașları yaptığı çalıșmada ise AA7075 alașımına değișen paso sayılarında EKAP uygulamıș ve artan paso sayısı ile çekme dayanımı ve kopma uzaması değerlerinin arttığını belirlemişlerdir (Horikiri vd., 2017). Suresh ve arkdaşları Al-Cu-Li alaşımı olan AA2195'e 4 paso EKAP uygulanması sonrasında malzemenin tane boyutunun oldukça inceldiğini, sertlik ve mukavemet değerlerinin önemli oranda artarken uzama değerlerinde ufak bir azalma olduğunu raporlamışlardır (Suresh vd., 2019). Shaeri ve arkadaşları ise AA7075 alaşımında EKAP'ın yaşlanma davranıșı üzerindeki etkilerini araştırmış ve ana yapının $60 \mu \mathrm{m}$ olan ortalama tane boyutunun 200-350 nm seviyelerine kadar indiğini, öte yandan tüm yaşlandırma koşullarında ana yapıya göre daha yüksek dayanım değerleri elde edildiğini belirlemişlerdir (Shaeri vd., 2015). Bu tür hafif alaşımların dışında çelik ve titanyum gibi daha mukavim 
malzemelerin de EKAP yöntemiyle bașarıyla proses edilebilindiği de literatürde görülmektedir. Maier ve arkadaşları yaptıkları çalışmada \% 0.09 C içeren düşük karbonlu bir çeliğe EKAP uygulamış ve EKAP sonrasında farklı sıcaklıklardaki ısıl işlemin içyapı üzerindeki etkilerini araştırmışlardır. Yapılan incelemeler sonucunda EKAP sonrası tane boyutunun önemli oranda azaldığı, $500{ }^{\circ} \mathrm{C}^{\prime}$ nin altındaki ısıl işlemlerde içyapı önemli oranda etkilenmezken, bu sıcaklığın üstüne çıkıldıkça tane irileşmesinin artarak meydana geldiği belirlenmiştir (Maier vd., 2013). Dobatkin ve arkadaşları östenitik paslanmaz çeliğe oda sıcaklığı ve $400{ }^{\circ} \mathrm{C}^{\prime}$ de EKAP işlemi uygulamışlar ve her iki sıcaklıkda da mikron altı seviyelerde ortalama tane boyutları elde ettiklerini ve mukavemet değerlerinin önemli oranda arttığını belirtmişlerdir (Dobatkin vd., 2018). Islamgaliev ve arkadaşları yüksek kromlu ferritik martenzitik çeliğine (12Cr-2W-2Ni-0.5Mo) EKAP uygulamışlar ve işlem sonrasında tane incelmesi elde ettiklerini ve mekanik özelliklerin geliştiğini belirtmişlerdir (Islamgaliev vd., 2019). Yanxia ve arkadaşları 2017 yılında yaptıkları çalışmalada ise saf titanyum alaşımına EKAP işlemi uygulamışlar ve EKAP sonrasnda tane boyutundaki incelmenin mekanik özellikler üzerinde geliştirici etkisini ortaya koymuşlardır. Öte yandan bu çalışmada EKAP sonrasında ultra ince taneli hale dönüşen saf titanyumun korozyon dayanımı konusunda ana duruma göre karışık sonuçlar elde edildiği ve bu konu üzerinde farklı çalıșmalarında ortaya konması gerektiği bildirilmiştir (Yanxia vd., 2017). Li ve arkadaşları Grade 4 titanyum alaşımına $300{ }^{\circ} \mathrm{C}^{\prime} \mathrm{de} 8$ paso EKAP işlemi uygulamış ve ișlem sonrașında $200 \mathrm{~nm}$ seviyelerinde tanelerden oluşan bir içyapı ve ana yapıya göre oldukça yüksek mukavemet değerleri elde ettiklerini rapor etmişlerdir (Li vd., 2014).

Yapılan bilimsel ve teknolojik incelemeler gemi imalatında kullanılan çeliklerin özellikle kimyasal yapısını etkilemeden mekanik özelliklerinin geliştirilmesine yönelik çalışmaların oldukça kısıtlı olduğunu göstermektedir. Yapılan bu çalışmalar incelendiğinde ise çalışmaların daha çok malzemelerin ısıl işlem sonrası mekanik özelliklerinin değișimine ya da sürtünme karıştırma işlemi (SKİ) sonrası malzemelerdeki mekanik özelliklerin değişimi üzerine yoğunlaştığı görülmektedir. Hayat ve Uzun yaptıkları çalışmada düşük karbonlu gemi inşaatı çeliğini farklı sıcaklıklarda tavlayarak su vermişlerdir. Yapılan incelemeler sonucunda tavlama sıcaklığı arttıkça su verme ișlemi sonrasında oluşan martenzit oranının arttı̆̆l, dayanım değerlerinin yükseldiği, darbe dayanımı değerlerinin ise azaldığını belirlemişlerdir (Hayat ve Uzun 2011). Sekban ve arkadaşları yaptıkları farklı çalışmalarda ise yine düşük karbonlu gemi inşa çeliğine sürtünme karıștırma işlemi (SKİ) uygulamışlar ve işlem sonrasında çeliğin ortalama tane boyutunun önemli oranda azaldığını, dayanım, sertlik, darbe dayanımı ve șekil verilebilirlik özelliklerinin de iyileştiğini bildirmişlerdir (Sekban vd., 2016; Sekban vd., 2018). EKAP yönteminin gemi inşaatı özelinde kullanımı incelendiğinde ise literatürde henüz bir çalıșmaya rastlanılmamıștır. Bu bağlamda bu çalışma da farklı çelik türlerine başarıyla uygulanan EKAP yöntemi gemi inşaatında yoğun bir kullanım alanına sahip düşük-orta mukavemetli (ASTM 131A) gemi inşa çeliğine EKAP yöntemi uygulanmış ve EKAP sonrası çeliğin içyapısal ve sertlik, mukavemet, aşınma ve şekil verilebilirlik gibi gemiler için önem teşkil eden mekanik özelliklerinde meydana gelen değişimler incelenmiştir.

\section{Materyal ve Yöntem (Material and Method)}

Çalışmada gemi inşaatından yoğun bir kullanıma sahip, sıcak hadde ürünü düşük-orta mukavemetli ASTM 131A $(0.16$ ağr \% C, 0.18 ağr \% Si, 0.7 ağr \% Mn, 0.011 ağr \% S, 0.018 ağr \% P, 0.09 ağr \% Cr, 0.14 ağr \% Mo, 0.04 ağr \% $\mathrm{Cu}, 0.04$ ağr \% V ve kalan Fe) çeliği kullanılmıştır. EKAP işlemleri 13 X 13 mm² kesit alanı ve 130 mm uzunluğa sahip numunelere $300^{\circ} \mathrm{C}^{\prime} \mathrm{de} 90^{\circ}$ iç açıya $(\Phi)$ ve $0^{\circ}$ dış yay açısına ( $\Psi$ ) sahip kalıpta $1 \mathrm{~mm} / \mathrm{s}$ basma hızında tek paso olarak gerçekleștirilmiştir. EKAP sırasında numunenin yüzeyi, kalıp ile arasındaki sürtünmeyi azaltmak amacıyla molibden sülfat katı yağlayıcı ile yağlanmıştır.

EKAP öncesi ve sonrası numunelerin içyapısal değişimlerini incelemek adına içyapı incelemeleri gerçekleştirilmiştir. EKAP sonrası numuneler elektro-erozyon yöntemi kullanılarak olası yönlenmeleri gözleyebilmek adına Şekil 1'de gösterildiği gibi ekstrüzyon doğrultusunda ve ekstrüzyon doğrultusuna dik olarak 2 farklı yönde çıkarılmıştır. EKAP öncesi ve sonrası içyapı incelemeleri için optik mikroskop (OM) ve taramalı elektron mikroskop (SEM) kullanılmıştır. Optik mikroskop incelemeleri için numuneler farklı numaralarda zımparalarla zımparalandıktan sonra $1 \mu \mathrm{m}$ boyutunda $\mathrm{Al}_{2} \mathrm{O}_{3}$ kullanılarak parlatılmış ve ardından \%3 Nital çözeltisinde $\left(\% 3 \mathrm{HNO}_{3}+\% 97 \mathrm{C}_{2} \mathrm{H}_{6} \mathrm{O}\right) 15 \mathrm{~s}$ bekletilerek dağlanmıştır. SEM incelemeleri için numuneler OM inceleme numuneleriyle benzer şekilde hazırlanarak JEOL 6400 marka SEM görüntüleme cihazında, 15 keV ve ikincil görüntüleme modu (SE) kullanılarak incelenmiştir.

EKAP öncesi ve sonrası numunelerdeki mekanik özellik değişimlerini belirlemek amacıyla sertlik, çekme, aşınma ve şekil verilebilirlik (Erichsen) deneyleri uygulanmıştır. Deneyler için numuneler, EKAP sonrası iş parçasından Şekil 1'de gösterilen konumlarda ve boyutlarda elektro-erozyon yöntemi kullanılarak çıkarılmıştır. Sertlik deneyleri Vickers sertlik ölçüm yöntemi kullanılarak Struers marka (Duramin 3) mikro-sertlik deney cihazında batıcı ucun basma yükü $300 \mathrm{~g}$ ve yük altında bekleme süresi $10 \mathrm{~s}$ seçilerek gerçekleştirilmiştir. Çekme deneyi numuneleri standart çekme numunesi boyutlarının EKAP sonrası elde edilen parçaya göre büyük gelmesinden ötürü standart dışı olarak köpek kemiği şeklinde (dog-bone shaped) ve 2 mm x 3 mm x 26 mm boyutlarında 
çıkarılmıştır. Deneyler Instron 3382 model bir üniversal çekme-basma deney cihazı kullanılarak oda sıcaklığında 5x10-4 s'-1'lik deformasyon hızında gerçekleştirilmiştir. Aşınma deneyleri 13 mm x 13 mm x 5 mm boyutlarında kesilen numuneler ile UTS Tribometer T30M-HT model aşınma test cihazında oda sıcaklığında gerçekleştirilmiştir. Deneylerde resprokeyting (iler-geri) hareketli aşınma deney tipi ve $6 \mathrm{~mm}$ çapında $\mathrm{Al}_{2} \mathrm{O}_{3}$ aşındırıcı bilyeler kullanılmıştır. Ayrıca deneyler $0.1 \mathrm{~m} / \mathrm{s}$ kayma hızında, $10 \mathrm{~N}$ yükleme değerinde ve $200 \mathrm{~m}$ kayma mesafesi seçilerek gerçekleștirilmiştir. Deneyler sonrası aşınma izlerinin 3 boyutlu tarama grafikleri Nanofocus $\mu$ scan marka optik profilometre ile çıkarılmıştır. EKAP sonrası numunelerin şekil verilebilirlik davranışındaki değişimleri belirlemek için ana malzeme ve EKAP sonrası numunelere Erichsen şekil verilebilirlik deneyleri uygulanmıştır. Numuneler 13 mm'lik kare formda ve $0.7 \mathrm{~mm}$ kalınlığında kesilerek Instron 3382 model çekme-basma deney cihazına bağlanan minyatürüze kalıp kullanılarak teste tabi tutulmuşlardır. Numunelerin yüzeyleri testler öncesinde zımparalanıp parlatılarak çizikler gibi çatlak başlangıcı oluşturabilecek yüzey kusurları giderilmiş ve 0,045 mm/s zımba ilerleme hızında yağlayıcı kullanılmadan Erichsen testleri gerçekleştirilmiştir. Deney sonrası numunelerin yüzeyler SEM kullanılarak incelenmiş ve optik profilometre ile 3 boyutlu tarama görüntüleri çıkarılmıştır. Yapılan tüm mekanik testlerde en az 3'er numune kullanılmış ve saçılım değerleri sonuçlar tablosuna yansıtılmıştır.

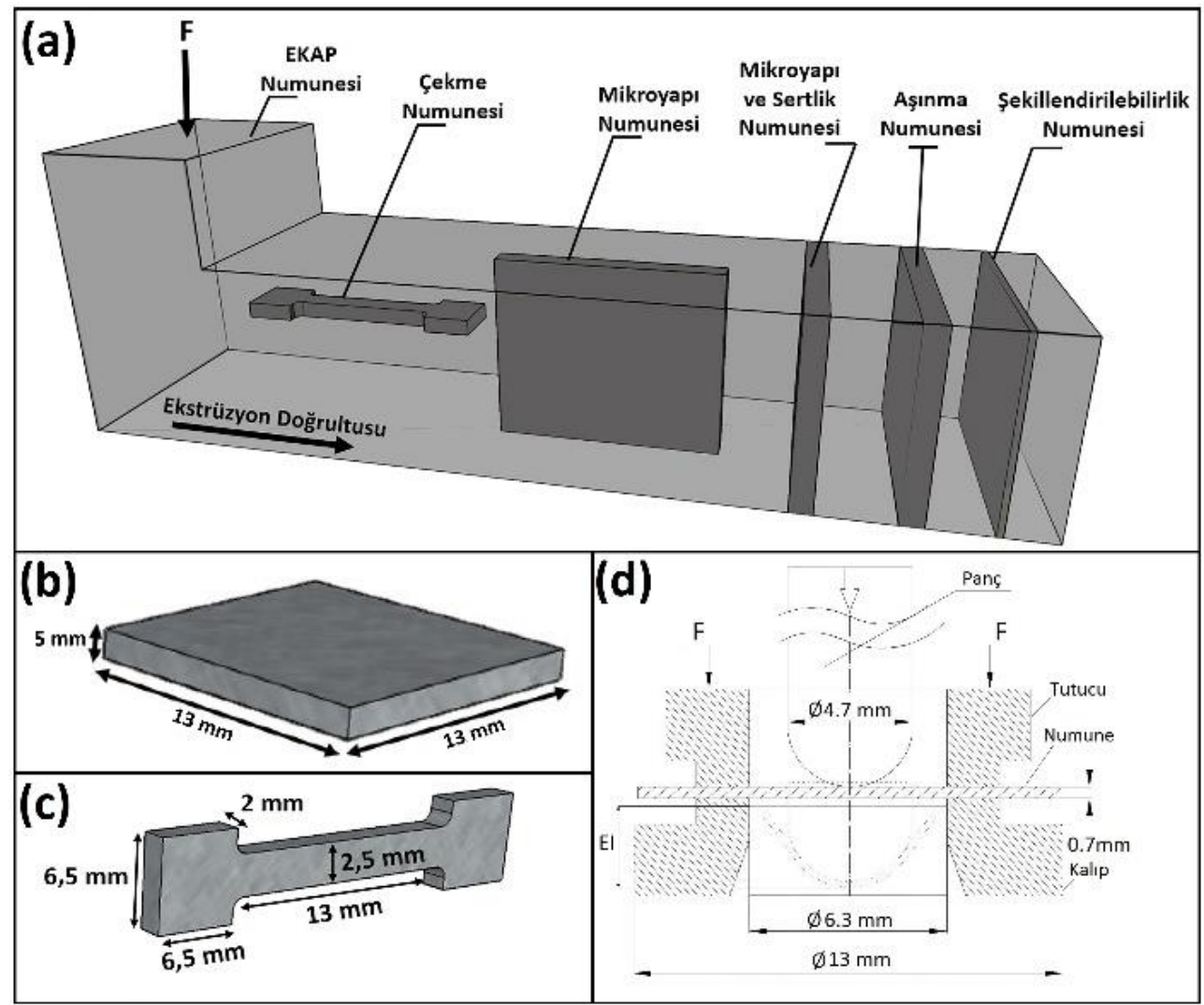

Şekil 1. (a) EKAP sonrası çıkarılan inceleme numunelerinin şematik gösterimi. Çıkarılan numunelerin boyutları: (b) içyapı, sertlik ve aşınma numunesi, (c) çekme numunesi ve (d) Erichsen kalıbı ve numunesi. ((a) Schematic illustration of the examination samples taken after EKAP. Dimensions of the extracted samples: (b) microsturture, hardness and wear sample, (c) tensile sample, and (d) Erichsen mold and sample.)

\section{Araştırma Bulguları (Research Findings)}

\section{1. İçyapısal Değişimler ve Malzemeye Uygulanan Deformasyon Miktarı (Microstructural Changes and Amount of Deformation Applied to the Material)}

Şekil 2' de çalışmada kullanılan düşük-orta mukavemetli gemi inşa çeliğinin içyapı görüntüleri verilmiştir. Görüleceği üzere EKAP öncesi malzeme içyapısı tipik bir düşük karbonlu alaşımsız çeliğin içyapısını sergilemekte ve açık renkli ferrit ve koyu renkli ince sementit lamelleri içeren perlit fazından meydana gelmektedir. Sıcak hadde ürünü olan malzemede beklenildiği üzere perlit fazı tane sınırları boyunca hadde doğrultusunda yönlenmiştir. Başlangıç yapısında içyapının ortalama ferrit tane boyutunun $25 \mu \mathrm{m}$ olduğu saptanmıștır. 

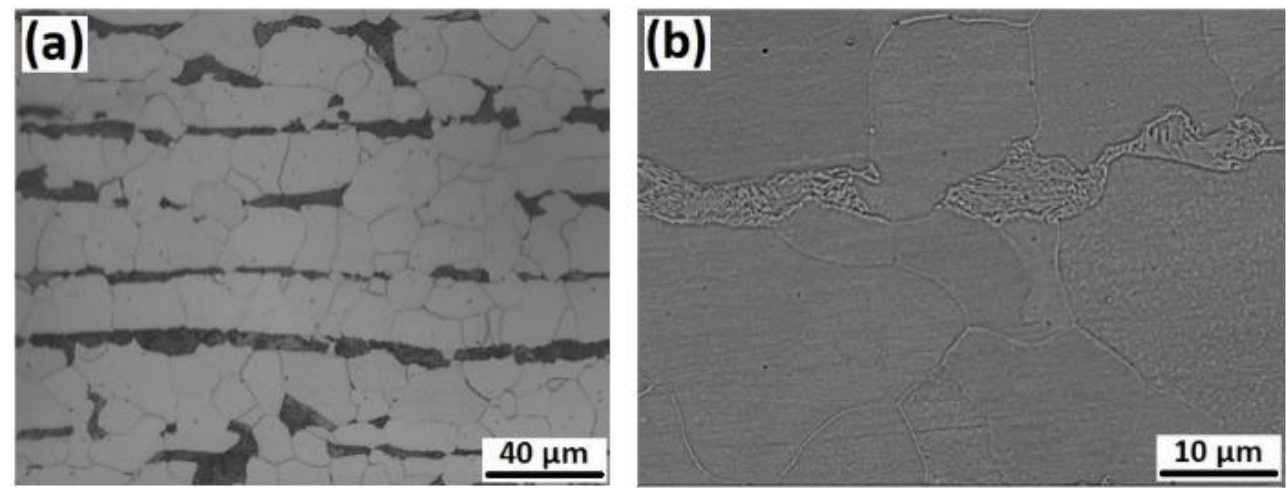

Şekil 2. Düşük-orta mukavemetli gemi inşaatı çeliğinin EKAP öncesi içyapı görüntüleri: (a) Optik mikroskop görüntüsü ve (b) SEM görüntüsü. (Microstructure of low-medium strength shipbuilding steel before ECAP: (a) Optical micrograph and (b) SEM micrograph.)

Tek paso EKAP sonrası ekstrüzyon doğrultusuna dik olarak çıkarılan numuneden oluşan içyapıya ait optik ve SEM resimleri Şekil 3 (a-b)'de verilmiştir. Görüleceği üzere EKAP sonrası düşük-orta mukavemetli gemi inşa çeliğinin içyapısı işlem sırasında meydana gelen yoğun plastik deformasyondan önemli ölçüde etkilenerek ana malzemeye göre oldukça incelmiş tanelerden oluşmaktadır. İşlem öncesi $25 \mu \mathrm{m}$ seviyelerinde ölçülen ortalama ferrit tane boyutunun EKAP sonrasında $7 \mu \mathrm{m}$ seviyesine indiği belirlenmiştir. Öte yandan ekstrüzyon doğrultusuna dik olarak çıkarılan numunelerin büyük oranda eş eksenli tanelerden oluştuğu da içyapı görüntülerinde açıkça görülmektedir.

EKAP sonrası ekstrüzyon doğrultusuna paralel yönde çıkarılan numunelerde oluşan içyapının optik ve SEM görüntüleri Şekil 3 (c-d)'de gösterilmektedir. Görüldüğü gibi ekstrüzyon doğrultusunda numune oldukça yüksek en boy oranına sahip ve yönlenmiş ferrit ve perlit tanelerinden oluşmaktadır. Literatür incelendiğinde de tek paso EKAP sonrası ekstrüzyon doğrultusunda iç yapının benzer şekilde yönlenmiş tanelerden oluştuğu görülebilmektedir (Iwahashi vd., 1998; Segal, 1999; Gholinia vd., 2000). Oluşan bu yönlenmiş içyapıya tek paso EKAP sırasında numunenin deformasyon düzleminden geçtiği esnada basit kayma ile deformasyona uğraması neden olmaktadır. ECAP kalıbı akış düzlemi üzerinde ekstrüzyon yönü ile 450'lik bir açıya sahiptir ve bu yüzden taneler kalıbın dikey ve yatay kanallarının kesişimlerindeki teorik kesme düzlemi boyunca uzamaktadırlar.
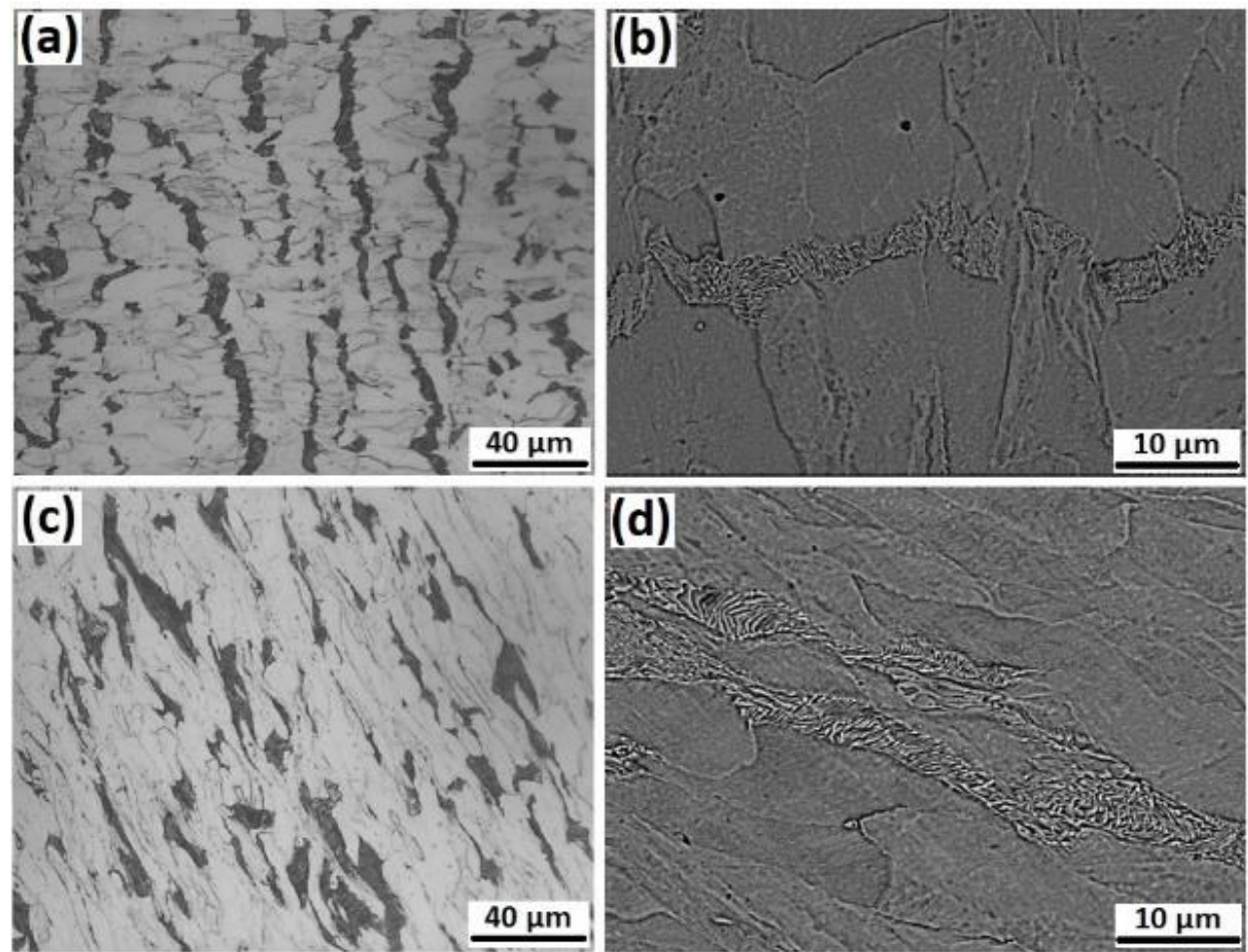

Şekil 3. EKAP sonrası düşük-orta mukavemetli gemi inşaatı çeliğinin içyapı görüntüleri: (a-b) Ekstrüzyon doğrultusuna dik olarak çıkarılan optik mikroskop ve SEM görüntüsü ve (c-d) Ekstrüzyon doğrultusunda çıkarılan optik mikroskop ve SEM görüntüsü. (Microstructures of low-medium strength shipbuilding steel after ECAP: (a-b) Optical microscope and SEM micrographs taken perpendicular to the extrusion direction and (c-d) Optical microscope and SEM micrographs taken from extrusion direction.) 
Tek paso EKAP sonrası malzemeye uygulanan deformasyon miktarı aşağıdaki formülle hesaplanabilmektedir. Formüldeki $(\Phi)$ iç açısına $0^{\circ}$ değerini, $(\Psi)$ dış yay açısı değerini ise $90^{\circ}$ değerini girdiğimizde EKAP uyguladığımız kalıp için tek paso sonrasında malzemeye uygulanan deformasyon miktarı yaklaşık 1 olarak elde edilmektedir.

$$
\varepsilon=1 / \sqrt{3}[2 \cot (\Psi / 2+\Phi / 2)+\Psi \operatorname{cosec}(\Psi / 2+\Phi / 2)]
$$

Değișen deformasyon miktarı ile malzeme tane boyutunda meydana gelen değişim grafiği Şekil 4'de görülmektedir. Görüleceği üzere deformasyon öncesi ( 0 deformasyon milktarında) $25 \mu$ m seviyelerinde ölçülen ortalama ferrit tane boyutu tek paso EKAP sonrasında (yaklaşık 1 olarak ölçülen deformasyon miktarı) $7 \mu \mathrm{m}$ seviyelerine kadar inmiştir.

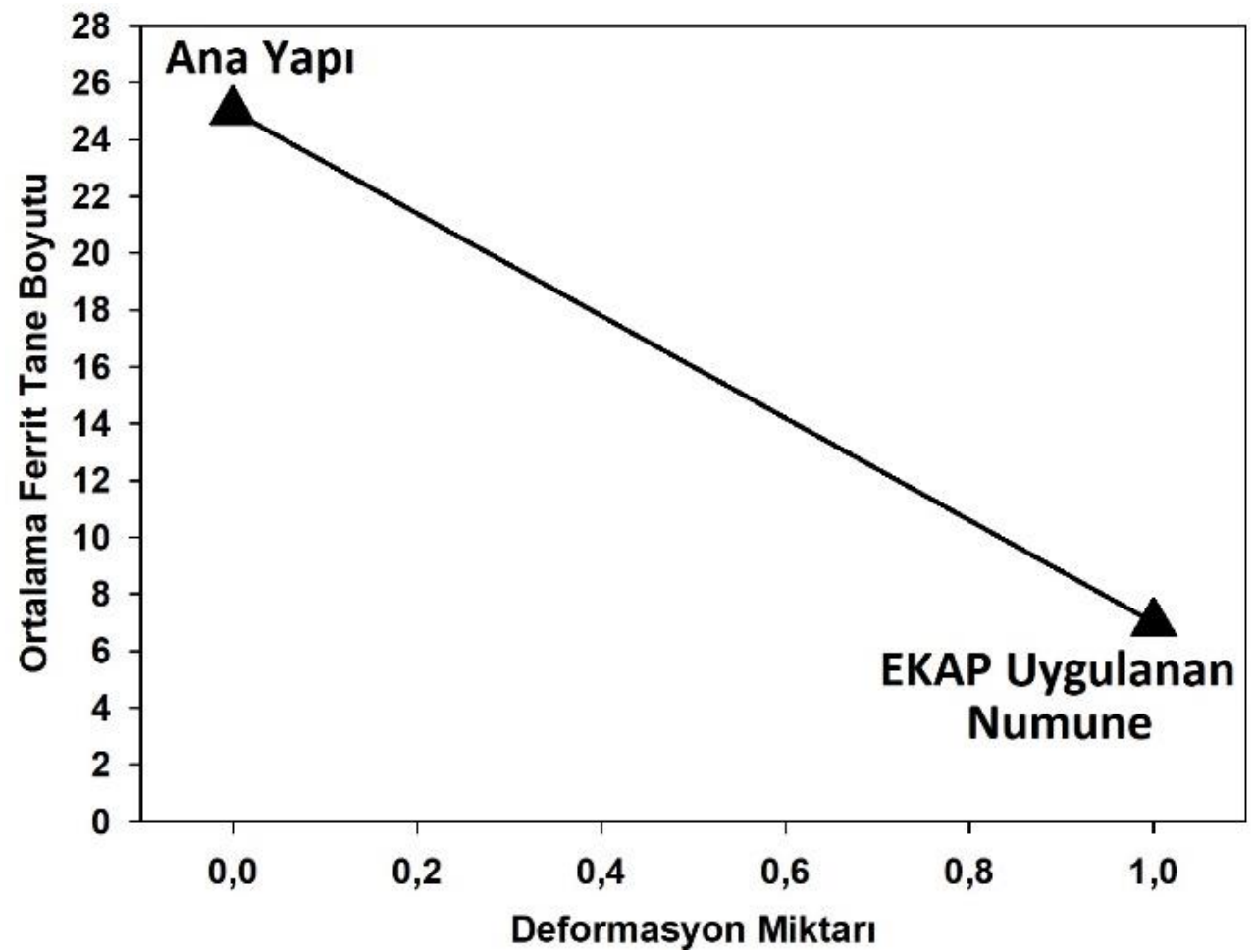

Şekil 4. Değișen deformasyon miktarı ile ortalama ferrit tane boyutundaki değișim grafiği. (Graph of change in average ferrite grain size with varying deformation amount.)

\subsection{Mekanik Özellikler (Mechanical Properties)}

\subsubsection{Sertlik ve Mukavemet (Hardness and Strength)}

Ana yapı ve EKAP sonrası ekstrüzyon doğrultusuna dik olarak çıkarılan numuneler ile yapılan sertlik

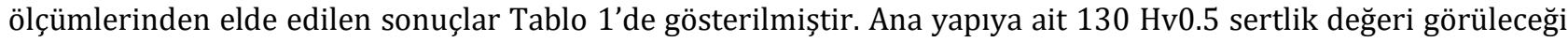
üzere EKAP sırasında oluşan yoğun plastik deformasyonun sonucu olarak incelen tane boyutu ve artan dislokasyon yoğunluğuna bağlı olarak 285 Hv0.5 seviyelerine çıkmıştır (Islamgaliev vd., 2019; Levin vd., 2019). Öte yandan EKAP sonrası çıkarılan numunenin tamamında homojen dağılımlı bir içyapı oluştuğundan numunenin ölçüm yapılan farklı tüm bölgelerinde sertlik değerlerinin 285 Hv0.5 seviyelerine çıtığı da belirlenmiștir.

Tablo 1. Ana yapı ve EKAP sonrası numunelerin mikrosertlik değerleri. (Microhardness values of base and ECAPed samples.)

\begin{tabular}{ccc}
\hline & Ana & $\begin{array}{c}\text { EKAP Uygulanan } \\
\text { Numune }\end{array}$ \\
\hline $\begin{array}{c}\text { Mikrosertlik } \\
\text { (Hv0.5) }\end{array}$ & $130 \pm 5$ & $285 \pm 11$ \\
\hline
\end{tabular}

Ana yapı ve tek paso EKAP sonrası yapıya ait gerilme-birim șekil değiștirme eğrileri Şekil 5'de ve bu eğrilerden elde edilen temel mekanik özellikler Tablo 2'de verilmiștir. Görüleceği üzere EKAP sonrası malzemenin mukavemet değerlerinde önemli oranda bir artış yaşanmıştır. Ana yapıda $284 \mathrm{MPa}$ olan akma dayanımı EKAP sonrası $414 \mathrm{MPa}$ seviyesine, $402 \mathrm{MPa}$ olan çekme dayanımı ise $795 \mathrm{MPa}$ seviyesine yükselmiştir. EKAP sonrası mukavemet değerlerinde elde edilen bu radikal artış temelde tane boyutunda meydana gelen incelmeden kaynaklanmaktadır (Kim vd., 2005; Niendorf vd., 2006; Saray vd., 2011). Öte yandan tane boyutunda meydana gelen radikal olmayan bu incelmeye karşın mukavemet değerlerinde yüksek oranda bir artış yaşandığı açıktır. 
Bunun nedeninin ise yeniden kristalleşmenin gerçekleşmediği sıcaklık değerlerinde uygulanan EKAP sırasında malzemede meydana gelen yoğun deformasyonun sonucu oluşması beklenen dislokasyon yoğunluğu artışının olduğu düşünülmektedir.

EKAP sonrası çeliğin uzama değerlerinde ise önemli bir oranda azalmanın olduğu ve ana yapıdaki uniform uzama değerinin \%21,1'den \%8,7'ye ve kopma uzaması değerinin ise \%36,4'den \%12,7'ye düştüğü belirlenmiştir. EKAP sonrası uzama değerlerindeki bu düşüşe tane incelmesi sonucu malzemedeki tane sınırı oranının artmasının neden olduğu düşünülmektedir (Saray vd., 2011). Öte yandan EKAP sonrası olduğu düşünülen dislokasyon yoğunluğundaki artışın da uzamadaki bu düşüşe etki eden bir diğer faktör olduğu düşünülmektedir.

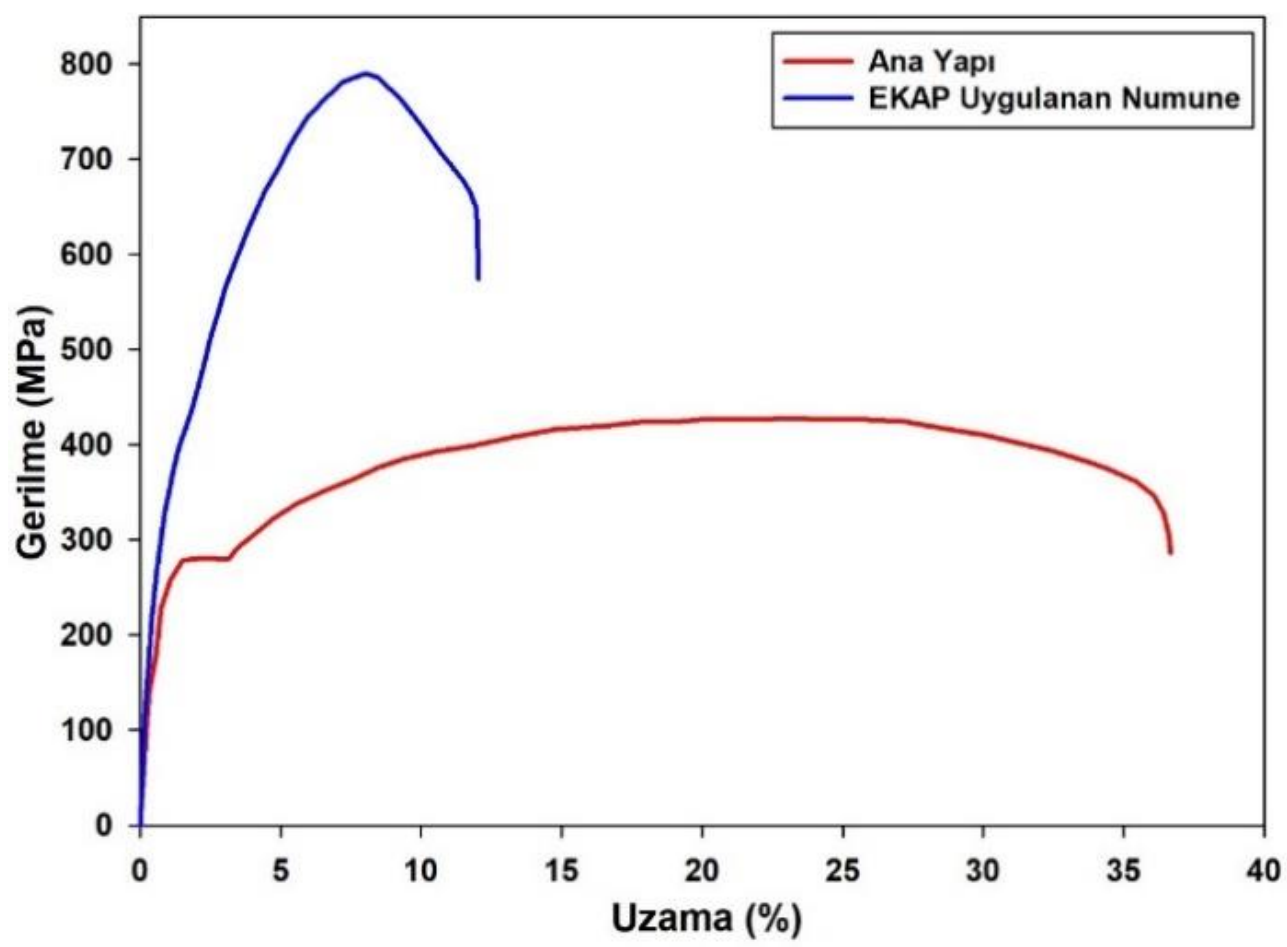

Şekil 5. Ana yapı ve EKAP sonrası numunelere ait mühendislik gerilme-uzama eğrileri. (Room temperature engineering stress-strain curves of base and ECAPed samples.)

Tablo 2. Ana yapı ve EKAP sonrası numunelere ait temel mukavemet ve uzama değerleri. (Main strength and elongation values of base and ECAPed samples.)

\begin{tabular}{ccccc}
\hline Durum & $\begin{array}{c}\text { Akma } \\
\text { Gerilmesi } \\
(\mathrm{MPa})\end{array}$ & $\begin{array}{c}\text { Çekme } \\
\text { Gerilmesi } \\
(\mathrm{Mpa})\end{array}$ & $\begin{array}{c}\text { Uniform } \\
\text { Uzama } \\
(\%)\end{array}$ & $\begin{array}{c}\text { Kopma } \\
\text { Uzaması } \\
(\%)\end{array}$ \\
\hline Ana Yapı & $284 \pm 08$ & $402 \pm 10$ & $21,1 \pm 0,9$ & $36,4 \pm 2$ \\
\hline EKAP & $414 \pm 07$ & $795 \pm 12$ & $8,7 \pm 0,7$ & $12,7 \pm 1$ \\
\hline
\end{tabular}

\subsubsection{Aşınma (Wear)}

Şekil 6'da ana yapı ve tek paso EKAP sonrası yapıya ait sürtünme katsayısının kayma mesafesi ile değişimini veren eğriler gösterilmiştir. Eğriler incelendiğinde eğrilerin ilk bölümünde sürtünme katsayısı değerlerinin keskin bir şekilde arttığı, daha sonra ise belli saçılımlarla kararlı bir duruma eriștiği görülmektedir. Sürtünme katsayısının kararlı kısma geçtiği bölüm karşılaştırıldığında EKAP sonrası yapının ana yapıya göre bir miktar daha düşük sürtünme katsayısı değerleri gösterdiği görülmektedir. Öyle ki kararlı kısımdaki ana yapıya ait sürtünme katsayısı değeri 0,51'den EKAP sonrası 0,44 değerlerine düşmüştür. EKAP sonrası çeliğin sürtünme katsayısında meydana gelen bu radikal olmayan azalmanın EKAP sonrası malzemenin sertlik ve mukavemet değerlerindeki artıştan kaynaklandığı düşünülmektedir (Aldajah vd., 2009; Yasavol ve Ramalho 2015). Bilindiği üzere sertlik artışı, aşınma esnasında birbiriyle sürtünen karşılıklı yüzeylerin birbirine nüfuzunu azaltmakta bu da plastik deformasyonun düşmesine neden olarak daha düşük sürtünme katsayılarının elde edilmesine neden olmaktadır (Aldajah vd., 2009; Yasavol ve Ramalho 2015). 


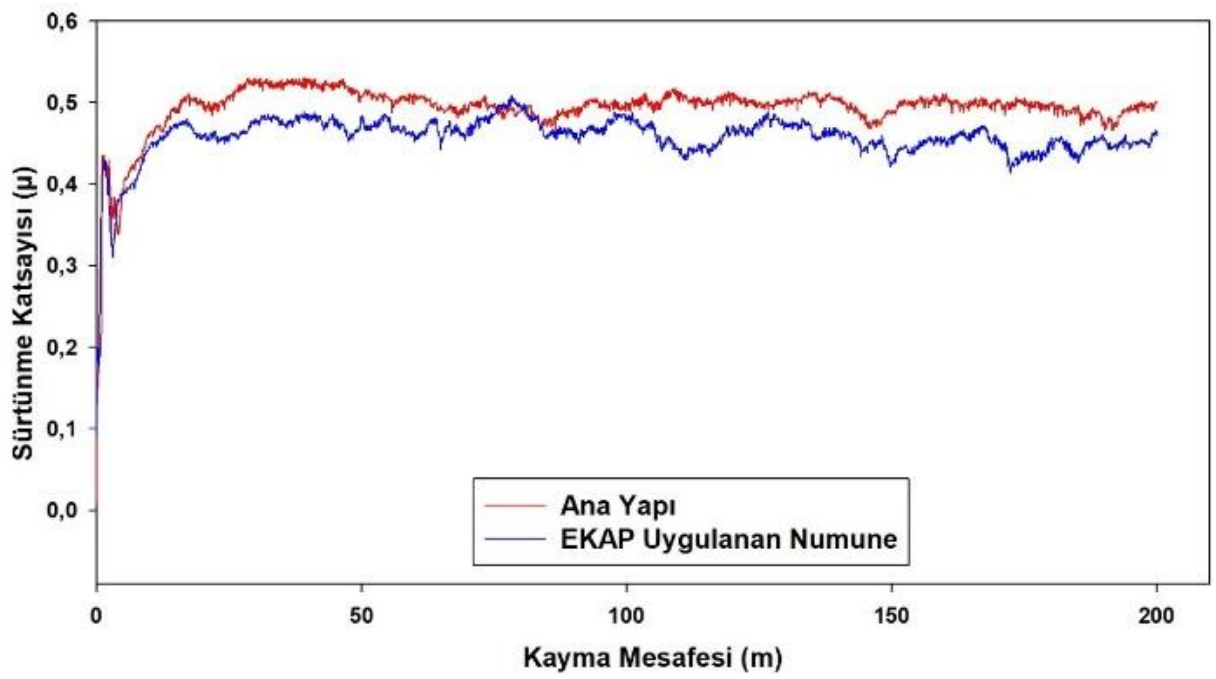

Șekil 6. Ana yapı ve EKAP sonrası yapıya ait sürtünme katsayısının kayma mesafesi ile değișimini gösteren eğriler. (The coefficient of friction vs. sliding distance curves for the low carbon steel before and after ECAP.)

Şekil 7'de ana yapı ve EKAP sonrası yapıya ait üç boyutlu aşınma izi görüntüleri ve aşınma derinliği-taranan mesafe eğrileri verilmiștir. 3 boyutlu așınma izleri ve așınma derinliği eğrisinden görülebileceği üzere EKAP sonrası numunenin aşınma derinliği azalmıștır. Ayrıca numunelerde kütle kaybı değerleri de ölçülmüş ve bu bulguları destekler sonuçlara ulaşılmıştır. Öyle ki aşınma deneyleri sonrasında ana yapıda meydana gelen 0,8 mg'lık kütle kaybı EKAP sonrasında 0,4 mg değerine düşmüştür. EKAP sonrası çeliğin aşınma direncinin artması veya ağırlık kaybının azalması ișlem sonrası elde edilen sertlik ve mukavemet artıșından kaynaklanmaktadır. Malzemenin sertlik ve akma mukavemetinde meydana gelen artıș, așınma deneyi sırasında așındırıcı bilye ile malzeme arasında meydana gelen plastik deformasyona karşı bir direnç oluşturarak malzemenin aşınma dayanımını arttırmaktadır (Huang vd., 2011).

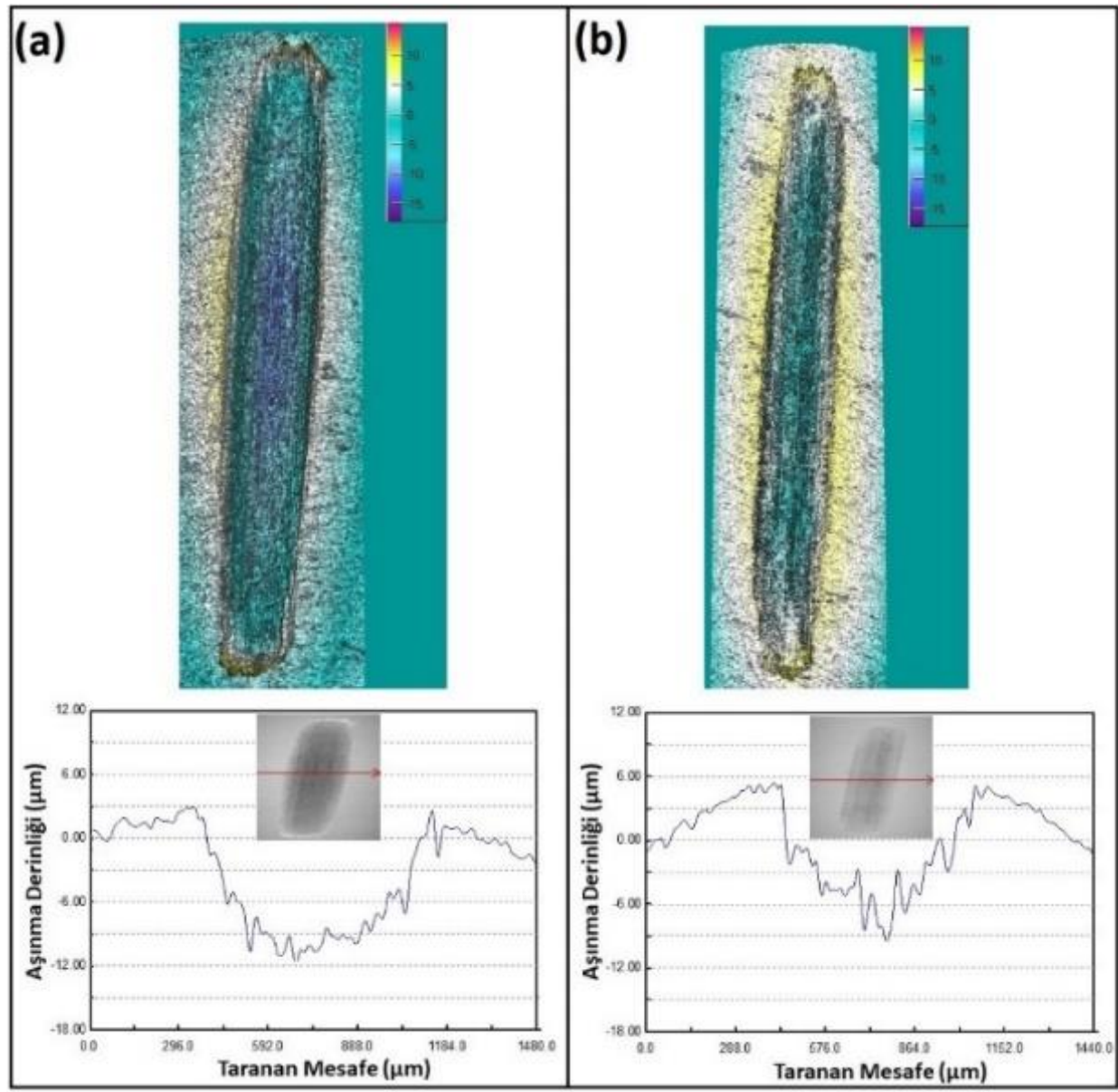

Şekil 7. Ana yapı ve EKAP sonrası yapıya ait üç boyutlu aşınma izi görüntüleri ve aşınma derinliği-taranan mesafe eğrileri: (a) Ana yapı ve (b) EKAP sonrası numune. (3D profilometric view of wear tracts and depth-scanned distance curves of the base and ECAPed structure: (a) Base and (b) ECAPed sample.) 


\subsection{3. Şekillendirilebilirlik (Formability)}

Erichsen şekillendirilebilirlik deneylerinden elde edilen zımba yükü (N) ve zımba sehimi (mm) eğrileri Şekil 8'de gösterilmiștir. Ayrıca bu eğrilerden elde edilen ve numunede çatlağın başlamasına kadar oluşan sehim değerini gösteren Erichsen indeksi (EI) ve bu sehim anındaki zımba basma yükünü veren ( $\mathrm{F}_{\mathrm{EI}}$ ) değerleri Tablo 3'de verilmiștir. Şekil 8 ve Tablo 3'den EKAP sonrası yapının ana yapıya göre zımba sehimi ve zımba yükü değerlerinde önemli bir düşüş meydana geldiği gözlemlenmektedir. Öyle ki ana yapıya ait 2,62 olan EI değeri tek paso EKAP sonrasında 0,68'e düşmüştür. Diğer taraftan EKAP sonrası yapıda EI değerindeki yüksek oranlı düşüşün bir neticesi olarak çatlağın başladığı andaki zımba yükü $\left(\mathrm{F}_{\mathrm{EI}}\right)$ değeri de ana yapınınkine oranla önemli oranda azalmıştır. Nitekim şekil verilebilirlik deneyi sırasında elde edilen gerekli $\mathrm{F}_{\mathrm{EI}}$ değeri ana yapıda $3974 \mathrm{~N}$ iken EKAP sonrasında 1652 N'a düşmüştür.

Bilindiği üzere tek paso EKAP işlemi sonrası yapı oldukça yönlenmiş tanelerden oluşmaktadır. Bu yapıdaki dislokasyonların da literatürden belli bir doğrultu üzerinde yığınlar halinde bulunduğu ve buna bağlı olarak sürekli alt tane sınırları olușturduğu da bilinmektedir (Saray vd., 2013; Saray vd., 2014). Bu sınırlar da nispeten fazla gerilme yığılması bölgeleri oluşturarak çatlak başlangıcı ve ilerlemesine neden olmaktadır (Cheng vd., 2003; Zhao vd., 2011). Bu etki de özellikle iki eksenli gerilmenin uygulandığı deformasyon halinde daha da hissedilir hale gelmektedir. Tüm bu bilgiler ışı̆̆ında tek paso EKAP işlemi sonrasında yapıda meydana gelen zımba sehimi ve zımba yükü değerlerindeki düşüşlerin nedenini anlamak mümkün olmaktadır.

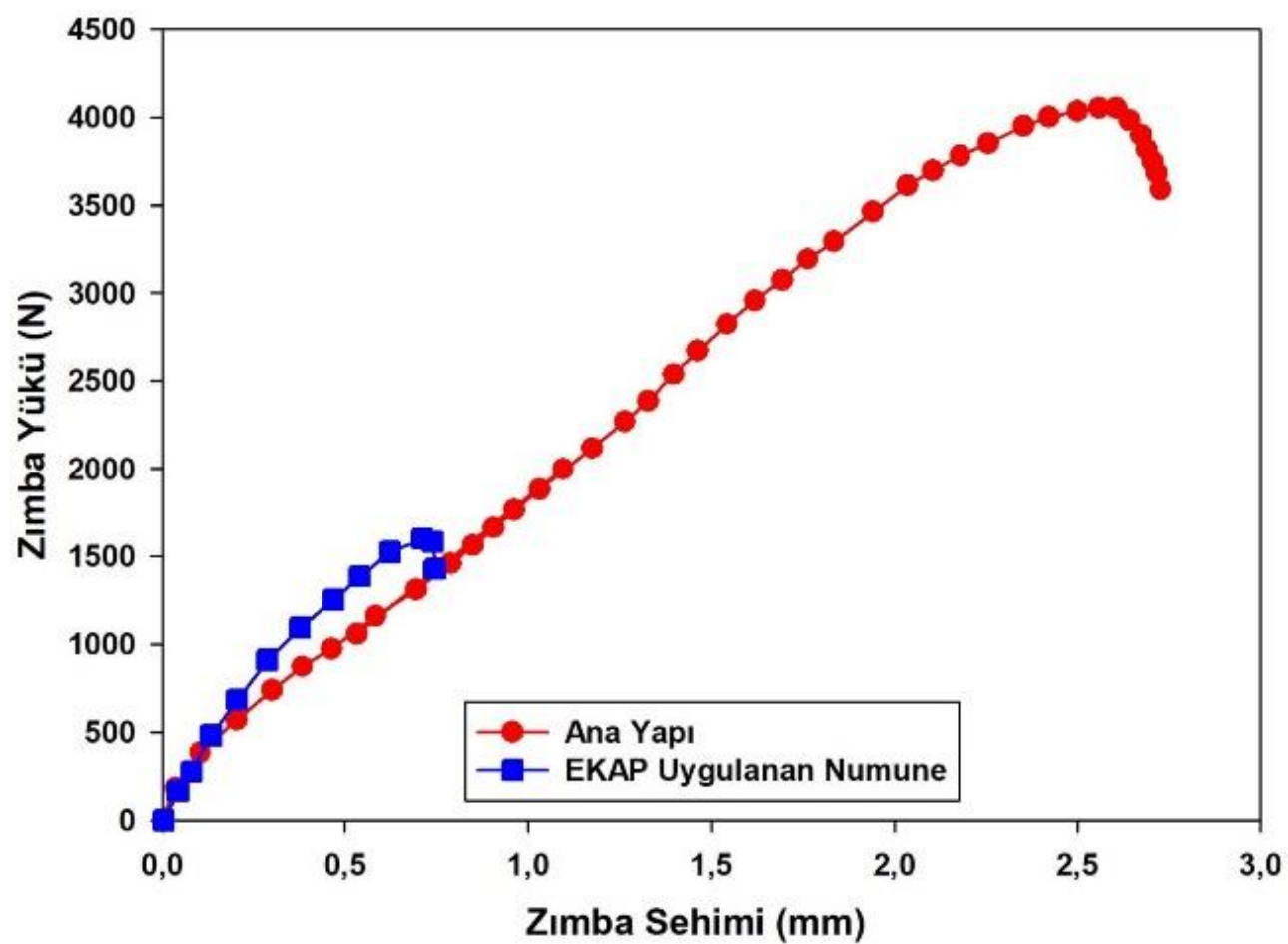

Şekil 8. Ana yapı ve EKAP sonrası yapıya ait zımba yükü - zımba sehimi eğrileri. (Punch load (F)-punch displacement (X) curves of base and ECAPed samples.)

Tablo 3. Erichsen deneyi sırasında ana yapı ve EKAP sonrası yapılardan elde edilen (EI) ve (FEI) değerleri. (Erichsen Index (EI) and punch force (FEI of base and ECAPed samples.)

\begin{tabular}{ccc}
\hline Durum & $\begin{array}{c}\text { Erichsen } \\
\text { Indeksi } \\
(\mathrm{EI})(\mathrm{mm})\end{array}$ & $\begin{array}{c}\text { Çatlak Başlangıcındaki } \\
\text { Zımba Yükü } \\
\left(\mathrm{F}_{\mathrm{EI}}\right)(\mathrm{N})\end{array}$ \\
\hline Ana Yapı & $2,62 \pm 0.2$ & $3974 \pm 41$ \\
\hline EKAP & $0,68 \pm 0.1$ & $1652 \pm 32$ \\
\hline
\end{tabular}

Erichsen deneyine tabi tutulmuş numunelerin yüzey SEM görüntüleri ve optik profilometre ile elde edilen üç boyutlu yüzey haritalandırması Şekil 9'da görülmektedir. Görüleceği üzere tek paso EKAP sonrasında Erichsen deneyine tabi tutulan numunelerin yüzey özelliklerinde ana yapıya kıyasla önemli değişimler ortaya çıkmıştır. Öyle ki ana yapıdaki portakal kabuğu etkisi EKAP sonrası numunelerde oldukça azalmıştır. Öte yandan ana yapıda 2,8 $\mu \mathrm{m}$ seviyesinde ölçülen yüzey pürüzlüğü değeri de tek paso EKAP işlemi sonrasında 1,1 $\mu \mathrm{m}$ seviyelerine inmiştir. Tek paso EKAP işlemi sonrasında numunelerin yüzey pürüzlüğündeki düşüşe işlem sonrasında meydana 
gelen tane incelmesinin ve bu tane incelmesi sonrasında taneler arasındaki kristalografik yönlenme farkının azalmasının neden olduğu düşünülmektedir (Becker, 1998). Bilindiği üzere yüzey pürüzlügü yüzeydeki taneler arasındaki yönlenme farkıyla orantılıdır (Becker, 1998; Wouters vd., 2005). Dolayısıyla tane incelmesinin sonucunda kesitteki tane boyutu birbirine yakın olan tane sayısı artarak taneler arası deformasyon uyumsuzluğu azalmakta ve böylelikle de yüzey pürüzlüğü azalmaktadır.

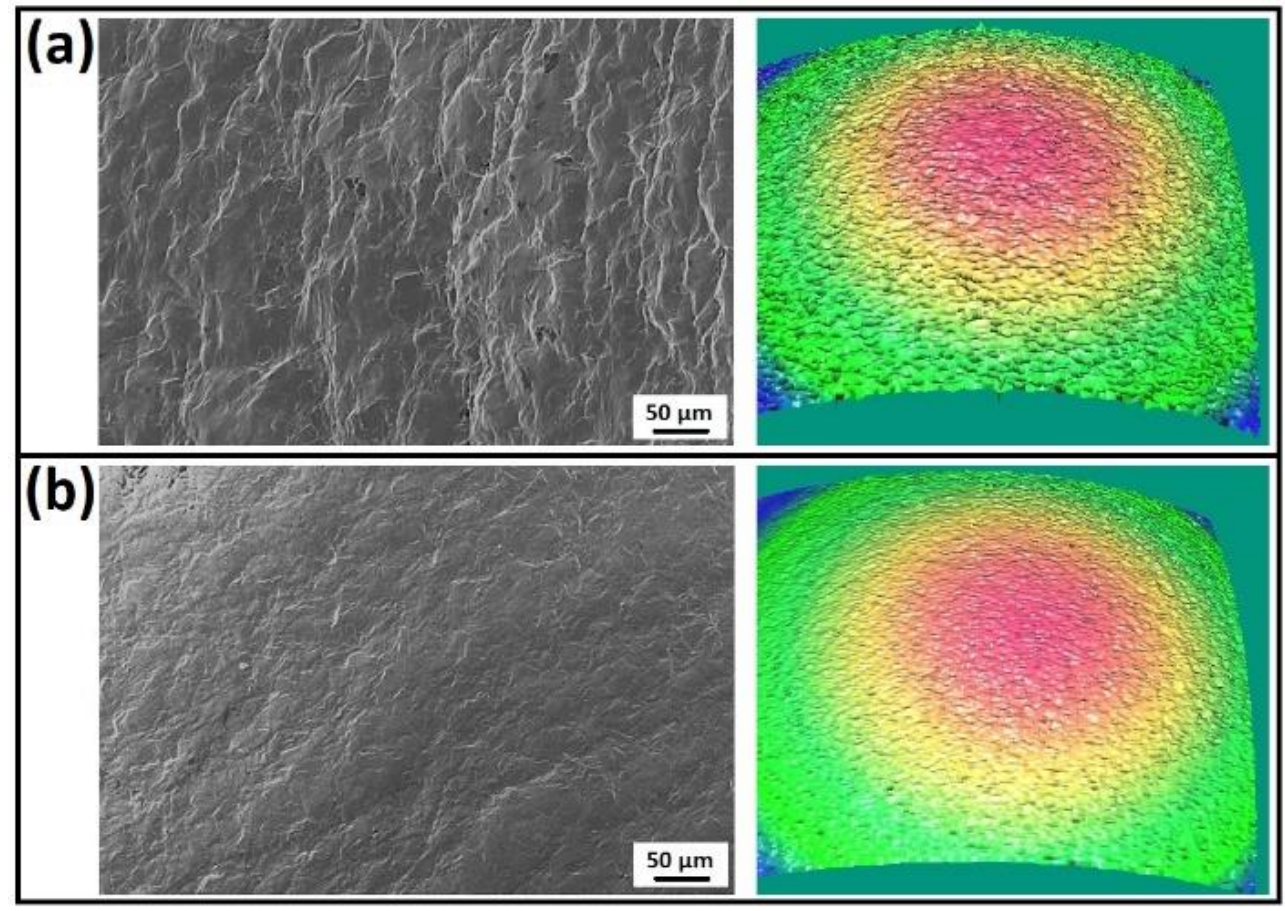

Şekil 9. Erichsen deneyine tabi tutulmuş numunelerin yüzey SEM görüntüleri ve optik profilometre ile elde edilen üç boyutlu yüzey haritalandırması: (a) Ana yapı ve (b) EKAP sonrası yapı. (SEM micrographs of free dome surfaces and 3D profilometric view of dome surfaces of: (a) base and (b) ECAPed samples.)

\section{Genel Sonuçlar (General Results and Discussions)}

Bu çalışma kapsamında gemi inşaatında kullanılan düşük-orta mukavemetli çeliğe eş kanallı açısal presleme (EKAP) yöntemi uygulanmış ve işlemin içyapı ve çeşitli mekanik özellikler üzerindeki etkisi incelenmiştir. Yapılan incelemeler sonucunda edilen genel sonuçlar aşağıda özetlenmiştir:

1- Ana yapıda $25 \mu \mathrm{m}$ seviyelerinde ölçülen ortalama ferrit tane boyutu tek paso EKAP işlemi sonrasında $7 \mu \mathrm{m}$ seviyesine inmiştir. Öte yandan ekstrüzyon doğrultusuna dik olarak çıkarılan numunelerin büyük oranda eş eksenli tanelerden oluşurken, ekstrüzyon doğrultusunda çıkarılan numunelerin oldukça yüksek en boy oranına sahip ve yönlenmiş ferrit ve perlit tanelerinden oluştuğu belirlenmiştir.

2- Ana yapıya ait $130 \mathrm{Hv0.5}$ sertlik değeri tek paso EKAP sonrasında işlem esnasında oluşan yoğun plastik deformasyonun sonucu olarak, incelen tane boyutu ve artan dislokasyon yoğunluğuna bağlı olarak 285 Hv0.5 seviyelerine çlkmıştır.

3- Tek paso EKAP öncesi ana yapıda $284 \mathrm{MPa}$ olan akma dayanımı tek paso EKAP sonrası tane incelmesi ve muhtemelen dislokasyon yoğunluğu artıșının bir sonucu olarak $414 \mathrm{MPa}$ seviyesine, $402 \mathrm{MPa}$ olan çekme dayanımı ise 795 MPa seviyesine yükselmiștir. Öte yandan EKAP sonrası çeliğin uzama değerlerinde ise önemli bir oranda azalmanın olduğu ve ana yapıdaki uniform uzama değerinin \%21,1'den \%8,7'ye ve kopma uzaması değerinin ise \%36,4'den \%12,7'ye düștüğü belirlenmiştir.

4- Tek paso EKAP sonrası yapının ana yapıya göre sürtünme katsayısı değerlerinin malzemede meydana gelen sertlik ve mukavemet artışının bir sonucu olarak bir miktar düştüğü ve 0,51 seviyesinden 0,44 seviyesine indiği belirlenmiştir. Ayrıca ana yapıda ölçülen 0,8 mg'lık kütle kaybının EKAP sonrasında 0,4 mg değerine düștüğü saptanmiştır.

5- Ana yapıya ait 2,62 olan EI değeri tek paso EKAP sonrasında oluşan yönlenmiş tanelerin çift eksenli gerilme esnasında malzemenin şekil verilebilirlik performansındaki olumsuz etkisi nedeniyle 0,68'e düşmüștür. Diğer 
taraftan EKAP sonrası yapıda EI değerindeki yüksek oranlı düşüşün bir neticesi olarak FE değeri de ana yapınınkine oranla önemli oranda azalmıştır. Nitekim şekil verilebilirlik deneyi sırasında elde edilen gerekli $\mathrm{F}_{\mathrm{EI}}$ değeri ana yapıda 3974 N iken EKAP sonrasında 1652 N’a düşmüştür. Öte yandan şekillendirilebilirlik deneyi sonrasında yüzey pürüzlügü tek paso EKAP işlemiyle tane incelmesiyle önemli ölçüde azalmıştır.

6- Gemi inşaatında malzemeler hem tek eksenli hem de çok eksenli gerilmelere maruz kalabilmektedir. Bu bağlamda hem tek eksenli gerilme durumunda (çekme eğrisinden) hem de çok eksenli gerilme durumunda (Erichsen şekillendirilebilirlik deneyinden) malzemenin deformasyon kabiliyetinin, meydana gelen pekleşme ile EKAP sonrasında önemli oranda azaldığı belirlenmiştir.

\section{Teşekkür (Acknowledgement)}

Calıșma kapsamında laboratuvar imkânlarının kullanılması noktasındaki katkılarından ötürü Karadeniz Teknik Üniversitesi Makine Mühendisliği Bölümü Öğretim Üyesi Prof. Dr. Gençağa PÜRÇEK'e teşekkürü bir borç bilirim.

\section{Çıkar Çatışması (Conflict of Interest)}

Yazar tarafından herhangi bir çıkar çatıșması beyan edilmemiștir. No conflict of interest was declared by the author.

\section{Kaynaklar (References)}

Aldajah, S.H., Ajayi, O.O., Fenske, G.R., David, S., 2009. Effect of friction stir processing on the tribological performance of high carbon steel. Wear, 267(1-4), 350-355.

Becker, R., 1998. Effects of strain localization on surface roughening during sheet forming. Acta Materialia, 46(4), $1385-1401$.

Bhadeshia, H. ve Honeycombe, R., 2011. Steels: Microstructure and Properties, Elsevier Science,.

Cheng, S., Spencer, J.A., Milligan, W.W., 2003. Strength and tension/compression asymmetry in nanostructured and ultrafinegrain metals. Acta Materialia, 51(15), 4505-4518.

Demirtas, M., Kawasaki, M., Yanar, H., Purcek, G., 2018. High temperature superplasticity and deformation behavior of naturally aged Zn-Al alloys with different phase compositions. Materials Science and Engineering: A, 730, 73-83.

Demirtas, M., Purcek, G., Yanar, H., Zhang, Z.J., Zhang, Z.F., 2015. Effect of equal-channel angular pressing on room temperature superplasticity of quasi-single phase $\mathrm{Zn}-0.3 \mathrm{Al}$ alloy. Materials Science and Engineering: A, 644, 17-24.

Demirtaş, M., 2017. Çinko-Esaslı Süperplastik Alaşımların Geliştirilmesi ve Yapısal, Mekanik ve Titreşim Sönümleme Davranıșlarının İncelenmesi. Trabzon, Karadeniz Teknik Üniversitesi.

Dobatkin, S.V., Skrotzki, W., Rybalchenko, O.V., Terent'ev, V.F., Belyakov, A.N., Prosvirnin, D.V., Raab, G.I., Zolotarev, E.V., 2018. Structural changes in metastable austenitic steel during equal channel angular pressing and subsequent cyclic deformation. Materials Science and Engineering: A, 723, 141-147.

Ebrahimi, M., Attarilar, S., Shaeri, M.H., Gode, C., Armoon, H., Djavanroodi, F., 2019. An investigation into the effect of alloying elements on corrosion behavior of severely deformed $\mathrm{Cu}$-Sn alloys by equal channel angular pressing. Archives of Civil and Mechanical Engineering, 19(3), 842-850.

Eyres, D.J., 2001. Ship Construction, Butterworth-Heinemann

Furukawa, M., Horita, Z., Nemoto, M., Langdon, T.G., 2001. Review: Processing of metals by equal-channel angular pressing. Journal of Materials Science, 36(12), 2835-2843.

Gholinia, A., Prangnell, P.B., Markushev, M.V., 2000. The effect of strain path on the development of deformation structures in severely deformed aluminium alloys processed by ECAE. Acta Materialia, 48(5), 1115-1130.

Hayat, F., Uzun, H., 2011. Effect of Heat Treatment on Microstructure, Mechanical Properties and Fracture Behaviour of Ship and Dual Phase Steels. Journal of Iron and Steel Research International, 18(8), 65-72.

Horikiri, G., Kitazumi, T., Natori, K., Tanaka, T., 2017. Improvement in mechanical properties of semi-solid AA7075 aluminum alloys by Equal-Channel Angular Pressing. Procedia Engineering, 207, 1451-1456.

Huang, S.J., Semenov, V.I., Shuster, L.S., Lin, P.C., 2011. Tribological properties of the low-carbon steels with different microstructure processed by heat treatment and severe plastic deformation. Wear, 271(5), 705-711.

Islamgaliev, R.K., Nikitina, M.A., Ganeev, A.V., Sitdikov, V.D., 2019. Strengthening mechanisms in ultrafine-grained ferritic/martensitic steel produced by equal channel angular pressing. Materials Science and Engineering: A, 744, 163-170.

Iwahashi, Y., Horita, Z., Nemoto, M., Langdon, T.G., 1998. The process of grain refinement in equal-channel angular pressing. Acta Materialia, 46(9), 3317-3331.

Kim, H.S., Ryu, W.S., Janecek, M., Baik, S.C., Estrin, Y., 2005. Effect of Equal Channel Angular Pressing on Microstructure and Mechanical Properties of IF Steel. Advanced Engineering Materials, 7(1-2), 43-46.

Klepaczko, J.R., Rusinek, A., Rodríguez-Martínez, J.A., Pęcherski, R.B. ve Arias, A., 2009. Modelling of thermo-viscoplastic behaviour of DH-36 and Weldox 460-E structural steels at wide ranges of strain rates and temperatures, comparison of constitutive relations for impact problems. Mechanics of Materials, 41(5), 599-621.

Langdon, T.G., 2007. The principles of grain refinement in equal-channel angular pressing. Materials Science and Engineering: A, 462(1), 3-11.

Levin, Z.S., Brady, B.G., Foley, D.C., Hartwig, K.T., 2019. Recrystallization behavior of tungsten processed by equal channel angular extrusion at low homologues temperature: Microstructure, hardness, and texture. International Journal of Refractory Metals and Hard Materials, accepted manuscript. 
Li, Y., Pang, Ng. H., Jung, H.D., Kim, H.E., Estrin, Y., 2014. Enhancement of mechanical properties of grade 4 titanium by equal channel angular pressing with billet encapsulation. Materials Letters, 114, 144-147.

Maier, G.G., Astafurova, E.G., Maier, H.J., Naydenkin, E.V., Raab, G.I., Odessky, P.D., Dobatkin, S.V., 2013. Annealing behavior of ultrafine grained structure in low-carbon steel produced by equal channel angular pressing. Materials Science and Engineering: A, 581, 104-107.

Niendorf, T., Canadinc, D., Maier, H.J., Karaman, I., Sutter, S.G., 2006. On the fatigue behavior of ultrafine-grained interstitial-free steel. International Journal of Materials Research, 97(10), 1328-1336.

Saray, O., Purcek, G., Karaman, I., Maier, H.J., 2013. Formability of Ultrafine-Grained Interstitial-Free Steels. Metallurgical and Materials Transactions A, 44(9), 4194-4206.

Saray, O., Purcek, G., Karaman, I., Maier, H.J., 2014. Improvement of formability of ultrafine-grained materials by post-SPD annealing. Materials Science and Engineering: A,. 619, 119-128.

Saray, O., Purcek, G., Karaman, I., Neindorf, T., Maier, H.J., 2011. Equal-channel angular sheet extrusion of interstitial-free (IF) steel: Microstructural evolution and mechanical properties. Materials Science and Engineering: A, 528(21), 6573-6583.

Segal, V.M., 1999. Equal channel angular extrusion: from macromechanics to structure formation. Materials Science and Engineering: A, 271(1), 322-333.

Sekban, D.M., Aktarer, S.M., Xue, P., Ma, Z.Y., Purcek, G., 2016. Impact toughness of friction stir processed low carbon steel used in shipbuilding. Materials Science and Engineering: A, 672, 40-48.

Sekban, D.M., Akterer, S.M., Saray, O., Ma, Z.Y., Purcek, G., 2018. Formability of friction stir processed low carbon steels used in shipbuilding. Journal of Materials Science \& Technology, 34(1), 237-244.

Shaeri, M.H., Shaeri, M., Salehi, M.T., Seyyedein, S.H., Abutalebi, M.R., 2015. Effect of equal channel angular pressing on aging treatment of Al-7075 alloy. Progress in Natural Science: Materials International, 25(2), 159-168.

Smirnov, I., Konstantinov, A., 2018. Influence of ultrafine-grained structure produced by equal-channel angular pressing on the dynamic response of pure copper. Procedia Structural Integrity, 13, 1336-1341.

Suresh, M., Sharma, A., More, A.M., Kalsar, R., Bisht, A., Nayan, N., Suwas, S., 2019. Effect of equal channel angular pressing (ECAP) on the evolution of texture, microstructure and mechanical properties in the Al-Cu-Li alloy AA2195. Journal of Alloys and Compounds, 785, 972-983.

Valiev, R.Z., Islamgaliev, R.K., Alexandrov, I.V., 2000. Bulk nanostructured materials from severe plastic deformation. Progr ess in Materials Science, 45(2), 103-189.

Valiev, R.Z., Langdon, T.G., 2006. Principles of equal-channel angular pressing as a processing tool for grain refinement. Progress in Materials Science, 51(7), 881-981.

Wouters, O., Vellinga, W.P., Tijum, R.V., de Hosson, J.T.M., 2005. On the evolution of surface roughness during deformation of polycrystalline aluminum alloys. Acta Materialia, 53(15), 4043-4050.

Yanxia, G., Aibin, M., Jinghua, J., Dan, S., 2017. Research Progress of Ultrafine-Grained Pure Titanium Produced by Equal-Channel Angular Pressing. Rare Metal Materials and Engineering, 46(12), 3639-3644.

Yasavol, N., Ramalho, A., 2015. Wear properties of friction stir processed AISI D2 tool steel. Tribology International, 91, 177183.

Zhao, Y., Topping, T., Li, Y., Lavernia, E.J., 2011. Strength and Ductility of Bi-Modal Cu. Advanced Engineering Materials, 13(9), 865-871. 